\title{
PURA RATU GEDE EMPU JAGAT DI DESA PAKRAMAN SANGKARAGUNG KECAMATAN JEMBRANA KABUPATEN JEMBRANA
}

\author{
Ni Nyoman Sariyani \\ STKIP Agama Hindu Singaraja, Singaraja, Indonesia \\ Email: sariyani123@gmail.com
}

\begin{abstract}
Abstrak
Tujuan penelitian ini adalah untuk mengetahui: 1) bentuk Pura Ratu Gede Empu Jagat, 2) fungsi Pura Ratu Gede Empu Jagat, 3) makna Pura Ratu Gede Empu Jagat di Desa Sangkaragung Kecamatan Jembrana Kabupaten Jembrana. Penelitian ini dirancang dengan penelitian emperik jenis deskriptif kualitatif. Teknik penentuan informan (sampel) yang digunakan adalah purposive sampling dengan Teknik snowball. Metode pengumpulan data yang digunakan dalam penelitian ini adalah observasi, wawancara, dan pencatatan dokumen. Sedangkan analisis data yang digunakan adalah: deskriptif kualitatif. Berdasarkan analisis data diperoleh hasil sebagai berikut. Bentuk Pura Ratu Gede Empu Jagat Desa Pakraman Sangkaragung adalah: 1) palinggih padmasana, 2) gedongan, 3) palinggih taksu, 4) palinggih Dewa Ayu Ganawati, 5) palinggih Dewa Ayu Padmawati, 6) piyasan, 7) bale pesandekan, dan 8) Bhagawan Penyarikan. Tetapi memiliki satu mandala saja, tidak seperti pura-pura yang lainnya yang memiliki tiga mandala. Fungsi Pura Ratu Gede Empu Jagat adalah : 1) fungsi religius, fungsi sosial. Makna Pura Ratu Gede Empu Jagat adalah : 1) makna astiti bhakti, 2) makna kesucian desa dalam pelaksaaan yadnya, 3) makna ajeg nilai adat budaya, 4) makna meningkatkan dan penghayatan umat terhadap ajaran-ajaran agama Hindu.
\end{abstract}

Kata kunci: Pura, Ratu Gede, Desa Pakraman.

\begin{abstract}
Key word: Ratu Gede Empu Jagat Temple

This study aimed to know: 1) the construction of Ratu Gede Empu Jagat Temple, 2) function of Ratu Gede Empu Jagat Temple, 3) the purpose of Ratu Gede Empu Jagat Temple at Sangkaragung village, Jembrana Regency. This study was designed descriptive qualitatively. Snowball Purposive sampling was used to determine the informant. There were three method of data collection used in this study namely: observation, interview, and document recording, then they were analyzed descriptive qualitatively. Based on the data analysis, there were result showed that, the construction of ratu Gede Empu Jagat Temple consisted of 1) palinggih padmasana (God manifestation), 2) Gedongan (storage room), 3) palinggih taksu (Prosperity manifestation), 4) palinggih dewa Ayu Ganawati (Specific name of God), 5) palinggih Dewa Ayu Padmawati (specific name of God), 6) piyasan (place of offerings), 7) bale pesandekan (rest station), and 8) bhagawan Penyarikan (specific name of God). This temple is only have one mandala (part of temple). The function of Ratu Gede Empu Jagat Temple are: 1) religious function, and social function. And the last, the meaning og Ratu Gede Empu Jagat Temple are: 1) religious purpose, 2) purpose of holiness, 3) purpose of the culture existence, and 4) purpose of improving people to do Hindu dogma.
\end{abstract}


Jurnal Widya Sastra Pendidikan Agama Hindu, Vol 4, No. 1, 2021

ISSN: 2656-7466

\section{PENDAHULUAN}

Pura memiliki peran yang sangat penting bagi kehidupan umat Hindu karena pura dijadikan sebagai tempat untuk memuja Tuhan. Keberadaan pura di Bali dapat dikelompokkan sesuai fungsinya yaitu pura yang fungsinya sebagai tempat suci untuk memuja Ida Sang Hyang Widhi, serta pura yang berfungsi sebagai tempat suci untuk memuja roh leluhur. Pura selain sebagai tempat persembahyangan juga dimanfaatkan untuk kegiatan lain seperti tempat istirahat tatkala umat melakukan perjalanan jauh, tempat berdikusi (Ber-Dharmatula), tempat umat Hindu mencetuskan perasaan masing-masing, dan sebagai media pendidikan.

Ardana (2000), dalam buku Pura Kahyangan Tiga menguraikan pura di bali dikelompokan sesuai ciri dan karakternya, antara lain : 1) Pura Umum yaitu pura yang memiliki ciri-ciri umum sebagai tempat pemujaan Ida Sang Hyang Widhi dengan segala Prabawa (Dewa). Pura yang tergolong umum ini dipuja oleh seluruh umat Hindu, sehingga sering disebut Pura Kahyangan Jagat. Pura yang tergolong Kahyangan Jagat adalah Pura Besakih, Pura Batur, dan Pura Sad Kahyangan, 2) Pura Teritorial yaitu : pura yang memiliki ciri kesatuan wilayah sebagai tempat pemujaan suatu desa adat yaitu Pura Kahyangan Tiga. Pura yang tergolong Pura Kahyangan Tiga adalah Pura Desa, Pura Puseh, Pura Dalem. 3) Pura Fungsional, pura ini memiliki karakter fungsional karena umatnya terikat oleh ikatan pekerjaan. Pura yang tergolong ke dalam pura ini: Pura Subak, Pura Melanting. 4) Pura Kawitan, yaitu pura ini mempunyai karakter yeng ditentukan adanya ikatan atau asal leluhur berdasarkan garis kelahiran, yang tergolong Pura Kawitan adalah Merajan atau Sanggah, Pura Panti, Pura Dadya.

Pura Ratu Gede Empu Jagat merupakan salah satu pura yang tergolong pura fungsional yang terdapat di Desa Pakraman Sangkaragung, Kecamatan Jembrana, Kabupaten Jembrana. Pura Ratu Gede Empu Jagat merupakan tempat memuja Ida Sang Hyang Widhi Wasa dalam Bhatara Iswara dalam wujud Barong. Nama Pura Ratu Gede Empu Jagat diambil dari nama/gelar sebuah Barong yang disakralkan di pura tersebut. Pada mulanya Barong ini merupakan tari seke Barong, di mana tarian Barong tersebut sebagai tarian utamanya. Sejalan dengan perkembangan kesenian Barong, mulai tumbuh kepercayaan masyarakat bahwa Barong ini memiliki suatu kekuatan gaib yang diyakini dapat menghindarkan masyarakat dari mara bahaya. Masyarakat menyebut kekuatan ini dengan sebutan Jero Gede. Keinginan para pemucuk adat dan pemuka masyarakat ini mendapat dukungan dari sebagian besar Krama Desa Pakraman Sangkaragung, seluruh krama Banjar Adat Samblong, ditambah lagi sebagian krama Banjar Adat Pangkung Gondang yang menyatakan diri sebagai Pekandel (Penyungsung tetap yang sifat turun temurun) dari pura ini. Selain sebagai tempat persembahyangan, pura ini juga diyakini sebagai tempat untuk meminta suatu permohonan positif seperti kesembuhan, keselamatan. Pura Ratu Gede Empu Jagat ini memiliki keistimewaan dan keunikan tersendiri. Dari beberapa pura yang terdapat di Desa Pakraman Sangkaragung, Kecamatan Jembrana, Kabupaten Jembrana ini, Pura Ratu Gede Empu Jagat selain dipercaya sebagai tempat meminta kesembuhan dari berbagai macam penyakit dan meminta keselamatan, Pura Ratu Gede Empu Jagat dianggap istimewa karena sangat dipercaya sebagai media nunas taksu kesenian seperti, jegog, rindik, joged bungbung, dan kesenian lainnya di mana taksu tersebut tidak bisa didapatkan di pura-pura lain yang ada di Desa Pakraman Sangkaragung, Kecamatan Jembrana, Kabupaten Jembrana. Sehingga warga sekitar khususnya para seniman seperti joged bungbung sering miminta keselamatan dan taksu di pura tersebut. Setiap warga sekitar yang meminta taksu kesenian di pura tersebut merasa sangat nyaman dan lancar ketika menjalankan kesenian tersebut dan merasa lebih "melik". Tetapi jika ingin taksu tersebut berlangsung lama sebaiknya rajin untuk bersembahyang di pura tersebut, karena jika hanya tangkil sekali maka taksu tersebutpun tidak bisa bertahan lama dan akan mengakibatkan 
Jurnal Widya Sastra Pendidikan Agama Hindu, Vol 4, No. 1, 2021

ISSN: 2656-7466

dampak negatif seperti yang dialami salah satu warga sekitar yang malas tangkil ke sana, akibatnya kesenian yang dia miliki kurang bisa dilihat orang lain dan akhirnya tidak pernah dipanggil oleh orang lain yang memiliki Upacara Manusa Yadnya seperti mengundang jegog, joged bumbung, rindik.

Keberadaan pura ini memberikan pengaruh yang positif terhadap masyarakat, hal ini dapat terlihat dari aktivitas persembahyangan yang terjadi, tidak hanya dilaksanakan pada saat piodalan melainkan setiap rahina, selain itu bagi masyarakat yang mengadakan suatu upacara Yadnya selalu memohon ijin di pura tersebut agar yadnya yang dilaksanakan dapat berjalan lancar. Tetapi ada beberapa hal yang kurang seperti buku sejarah pura yang sampai sekarang belum dimiliki oleh pengempon pura, hanya Pengelingsir yang mengetahui sejarah persis dari pura tersebut, sehinga generasi muda tidak dapat mengetahui persis sejarah berdirinya pura tersebut.

Untuk mengkaji bentuk pura, fungsi pura, dan makna pura Ratu Gede Empu Jagat di desa Pakraman Sangkaragung Kecamatan Jembrana Kabupaten Jembrana. Beberapa konsep penting yang terkait dengan gejala penelitian sebagai berikut. Prihal Pura adalah tempat suci yang khusus untuk tempat persembahyangan oleh umat Hindu. Pura Ratu Gede Empu Jagat merupakan salah satu pura yang tergolong fungsional yang terdapat di Desa Pakraman Sangkaragung, penyungsung pura ini memiliki profesi kesenian. Dibangunnya pura ini diawali dari tumbuhnya kepercayaan masyarakat terhadap kekuatan gaib dari Barong tersebut. Mulanya Barong tersebut merupakan barong kesenian yang dimiliki Sekehe Barong Desa Pakraman Sangkaragung yang digunakan pentas. Diperkirakan pada tahun 1850 pernah seluruh Desa Pakraman Sangkaragung terjangkit wabah penyakit, setelah meminta obat dan petunjuk Barong tersebut akhirnya seluruh masyarakat dapat terselamatkan. Dari kejadian inilah masyarakat mulai sering menghaturkan upakara pada Barong tersebut. Juga dari kejadian ini Bapak I Nengah Korya dengan rela menyumbangkan tanahnya untuk membangun Pura Ratu Gede Empu Jagat. Pada tahun 1968 mulailah pembangunan pura ini dengan swadaya masyarakat dengan segala kesederhanaannya. Pada tahun 1970 pura itu dipelaspas (Ngenteg Linggih). Piodalan di pura ini pada Tumpek Wayang (Sabtu Kliwon wuku Wayang). Tradisi Nyolahang ini selalu dilaksanakan oleh masyarakat Desa Pakraman Sangkaragung, satu hari sebelum piodalan (Kalipaksa) di Pura Ratu Gede Empu Jagat. Desa Pakraman adalah kesatuan masyarakat hukum mempunyai susunan asli, hak asal-usul yang bersifat istimewa bersumber pada Agama Hindu, Kebudayan Bali, berdasarkan Tri Hita Karana, mempunyai Khayangan Tiga atau Kahyangan Desa. Desa Pakraman Sangkaragung adalah sebuah desa yang telah mempunyai aturan-aturan tata krama yang dibuat atau berlaku bagi seluruh warga desa. Dalam kaitannya dengan judul penelitian ini ada beberapa teori yang digunakan antara lain: teori religi, teori simbol, teori struktur-fungsional, teori makna.

\section{METODE}

Penelitian ini dirancang dengan penelitian emperik jenis kualitatif. Subjek penelitiannya adalah masyarakat yang ada di desa pakraman Sangkaragung kecamatan Jembrana Kabupaten Jembrana. Informan dalam penelitan ini adalah Tokoh-tokoh masyarakat, Bendesa Adat, dan Prajuru Adat di Desa Sangkaragung. Teknik penentuan informan ( Sampel) yang digunakan adalah purposive sampling dengan teknik snowball. Metode pengumpulan data yang digunakan dalam penelitian ini adalah observasi, wawancara, dan dokumentasi (kepustakaan). Sedangkan analisis data yang digunakan adalah deskriptif kualitatif.

\section{HASIL DAN PEMBAHASAN}


Jurnal Widya Sastra Pendidikan Agama Hindu, Vol 4, No. 1, 2021

ISSN: 2656-7466

\section{Bentuk Pura Ratu Gede Empu Jagat Di Desa Pakraman Sangkaragung Kecamatan Jembrana Kabupaten Jembrana}

Pura Ratu Gede Empu Jagat terdiri dari satu mandala yaitu Utama Mandala yang dikelilingi oleh tembok dengan luas $12 \times 20$ meter dengan dua buah pintu yang berfungsi sebagai pintu masuk dan pintu ke luar. Palinggih adalah stana atau tempat duduk Ida sang Hyang Widhi Wasa. Pura Ratu Gede Empu Jagat ini terdiri dari enam palinggih, dan dua bale yaitu 1) Palinggih Padmasana, 2) Palinggih Gedongan, 3) Palinggih Taksu, 4) Palinggih Dewa Ayu Ganawati, 5) Palinggih Dewa Ayu Padmawati, 6) Bale Piyasan, 7) Bale Pesandekan/Bale Tajuk, dan 8) Palinggih Ratu Bhagawan Penyarikan.

Untuk lebih jelasnya keberadaan dari Pura Ratu Gede Empu Jagat ini akan dijelaskan fungsi masing-masing palinggih dan bangunan yang ada pada Pura Ratu Gede Empu Jagat. Fungsi masing-masing palinggih dan bangunan adalah:

\section{1) Palinggih Padmasana}

Padmasana berarti simbol yang menggambarkan kedudukan Hyang Widhi. Palinggih Padmasana ini terletak di bagian timur laut menghadap ke barat daya, memakai dasar Bhedawangnala, bertingkat lima di puncaknya ada satu ruang. Bangunan ini berfungsi juga sebagai niyasa stana Sang Hyang Siwa Raditya atau Sanghyang Tripurusa stana Ida Sang Hyang Widhi dan merupakan simbolis dari keesaan Ida Sang Hyang Widhi. Di pura ini tidak semata-mata tempat memuja Ratu Gede Empu Jagat, tetapi juga sebagai tempat memuja Ida Sang Hyang Widhi Wasa, yang merupakan penguasa tertinggi, sedangkan Ida Ratu Gede Empu Jagat adalah manifestasi dari kemahakuasaan Ida Sang Hyang Widhi.

\section{2) Palinggih Gedongan}

Palinggih Gedongan terletak di bagian utara menghadap ke selatan. Di dalam Gedongan inilah tersimpan Barong Ratu Gede Empu Jagat. Gedongan ini berfungsi sebagai tempat khusus untuk memuja Ida Sang Hyang Widhi Wasa dalam manifestasinya yang diberi gelar Ida Ratu Gede Empu Jagat, yaitu kemahakuasaan beliau dalam memberikan keselamatan, dan kesejahteraan bagi umat manusia utamanya dalam menolak bala.

\section{3) Palinggih Taksu}

Pelinggih ini terletak di bagian barat laut menghadap ke selatan. Palinggih Taksu yang berada di pura Ratu Gede Empu Jagat merupakan stana Ida Bhatara Bhagawan Wiswakarma sebagai pemberi kewibawaan. Palinggih tersebut tempat memohon kesidian atau keberhasilan dari semua jenis profesi baik sebagai seniman, petani, pedagang, dan pemimpin masyarakat.

\section{4) Palinggih Dewa Ayu Ganawati}

Palinggih Dewa Ayu Ganawati terletak di bagian timur mengadap ke barat. Palinggih ini berfungsi sebagai tempat memuja Widyadari yang bergelar Dewa Ayu Ganawati yang mempunyai kekuatan sebagai sumber kekuatan gaib yang dapat memberikan kharisma (daya tarik) bagi kesenian, sehingga kesenian mempunyai daya tarik yang kuat dan disenangi oleh penonton.

\section{5) Palinggih Dewa Ayu Padmawati}

Palinggih Dewa Ayu Padmawati ini terletak di bagian timur menghadap ke barat,

Palinggih ini berfungsi sebagai tempat memuja Widyadari yang bergelar Dewa Ayu Padmawati. Dan juga sebagai tempat memohon taksu.

\section{6) Bale Piyasan}


Jurnal Widya Sastra Pendidikan Agama Hindu, Vol 4, No. 1, 2021

ISSN: 2656-7466

Bale Piyasan di Pura ini terletak di bagian barat menghadap ke timur, bangunan ini dipergunakan sebagai tempat Upakara (Banten)yang akan dihaturkan pada saat piodalan, dan piyasan ini berfungsi pula sebagai tempat Sulinggih (Pendeta) pada saat melaksanakan upacara.

\section{7) Bale Pesandekan/Bale Tajuk}

Bale Pesandekan terletak di bagian selatan, bangunan ini berfungsi sebagai tempat istirahat, sementara persembahyangan belum dimulai, dan juga sebagai tempat sembahyang bagi pemedek yang ingin sembahyang di Pura Ratu Gede Empu Jagat.

\section{8) Palinggih Ratu Bhagawan Penyarikan}

Palinggih ini terdapat di bagian luar pura menghadap ke timur. palinggih ini berfungsi sebagai juru tulis dan juru arah kedewataan, di saat piodalan. Palinggih Ratu Bhagawan Peyarikan tiada lain adalah Tuhan dalam manifestasinya sebagai penuntun umat manusia menapaki tahapan-tahapan hidupnya untuk mewujudkan tujuan hidupnya di dunia mencapai Tri Purusa Artha.

\section{Fungsi Pura Ratu Gede Empu Jagat Di Desa Pakaraman Sangkaragung Kecamatan Jembrana Kabupaten Buleleng}

\section{1) Fungsi Religus}

Pura Ratu Gede Empu Jagat memiliki fungsi religus di antaranya sebagai media Nunas Taksu kesenian, sebagai tempat untuk memohon suatu permohonan positif seperti kesembuhan, keselamatan, dan kelancaran dalam setiap kegiatan seperti menghadapi ujian, pertandingan dan melaksanakan Upacara Yadnya.

\section{2)Fungsi Sosial}

Keberadaan Pura Ratu Gede Empu Jagat dapat memberikan pengaruh yang positif bagi masyarakat hal ini terlihat dari setiap diadakannya piodalan dan tradisi Ngelawang, masyarakat banjar selalu atur ayah(ngayah) di pura ini, dari sinilah dapat dilihat antara masyarakat satu sama yang lain dapat saling bertinteraksi mengenal satu sama lain sehingga terjalin persaudaraan yang baik.

\section{Makna Pura Ratu Gede Empu Jagat Di Desa Sangkaragung Kecamatan Jembrana Kabupaten Jembrana \\ 1) Makna Astiti Bhakti}

Keberadaan pura ini di Desa Sangkaragung sebagai media yang sangat membantu dalam mendekatkan diri kepada Ida Sang Hyang Widhi Wasa. Masyarakat di pura ini berpendapat walaupun yang dipuja berwujud Barong, bukanlah berarti Barong itu yang disembah, mereka mempunyai keyakinan bahwa Ida Sang Hyang Widhi dapat menunjukkan kemahakuasaan beliau pada segala yang ada di alam ini. Hampir setiap hari di pura ini terjadi kegiatan keagamaan seperti: matur piuning bagi masyarakat yang memiliki karya (upacara yadnya, yang akan bepergian jauh, ujian, pertandingan, biasanya selalu matur piuning di pura ini, dengan tujuan .memohon keselamatan atas segala kegiatan yang dilakukan.

\section{2) Makna Kesucian Desa Dalam Pelaksanaan Yadnya}

Keberadaan Pura Ratu Gede Empu Jagat di Desa Pakraman Sangkaragung juga dapat meningkatkan kesucian desa. Hal ini dibuktikan dengan dilaksanakannya Tradisi Ngelawang di desa ini. Tradisi Ngelawang ini dilaksanakan dengan Ngiring Barong Ratu Gede Empu Jagat 
Jurnal Widya Sastra Pendidikan Agama Hindu, Vol 4, No. 1, 2021

ISSN: 2656-7466

mengelilingi desa, hal ini dipercaya dapat menetralisir hal negatif desa, juga dibarengi dengan upacara pecaruan di masing-masing pekarangan rumah. Masyarakat melakukan Upacara Yadnya merupakan langkah yang diyakini sebagai kegiatan beragama yang sangat penting, karena Yadnya merupakan penyangga untuk menjaga keseimbangan bumi. Pemeliharaan kehidupan di dunia ini dapat berlangsung terus sepanjang Yadnya terus dilakukan oleh umat manusia.

\section{3) Makna Ajeg Nilai Adat Budaya}

Keberadaan Pura Ratu Gede Empu Jagat dapat meningkatkan dan melestarikan kesenian yang ada di Desa Pakraman Sangkaragung. Hal ini dibuktikan dari banyaknya pemedek yang berasal dari Desa Pakraman ini yang mapinunas Taksu di pura ini, selain itu banyak juga kesenian yang berasal dari luar desa maupun dari luar Kabupaten yang nunas Taksu di pura ini. Ada beberapa kesenian dari desa lain yang Taksunya bersumber dari Pura ini, seperti Taksu Jegog, Bumbung, Gong, Pregina (tari), Angklung, Rindik yang berasal dari desa-desa se-Kabupaten Jembrana. Ada juga yang berasal dari luar Kabupaten seperti dari Desa Magati Tabanan untuk nunas Taksu sekaa Bumbung. Di Desa Pakraman ini ada satu kesenian yang terkenal hingga ke manca negara yaitu Jegog Suar Agung.

\section{4) Makna Meningkatkan dan Penghayatan Umat Terhadap Ajaran-Ajaran Agama Hindu}

Keberadaan Pura Ratu Gede Empu Jagat di Desa Pakraman Sangkaragung dapat meningkatkan pengetahuan dan penghayatan umat terhadap ajaran agama Hindu. Hal ini dibuktikan dari pelaksanaan Dharma Tula di Pura Ratu Gede Empu Jagat ini dapat memberikan arahan-arahan tentang ajaran agama Hindu kepada masyarakat. Selain itu di Pura ini juga dilaksanakan semadi pada saat Rahina Siwalatri, sehingga masyarakat dapat menghayati ajaran-ajaran agama Hindu bersama-sama dengan dituntun oleh pelaku agama.

\section{SIMPULAN DAN SARAN}

Berdasarkan analisis di atas dapat disimpulkan bahwa:

1) Bentuk Pura Ratu Gede Empu Jagat diawali dari dibangunnya pura ini yang berlatar belakang dari keyakinan pada masyarakat terhadap suatu kekuatan pada Barong dapat menghindarkan manusia dari mara bahaya hal ini telah dibuktikan dari setiap kali masyarakat memohon sesuatu selalau diberikan kelancaran. Nama atau sebutan Pura Ratu Gede Empu Jagat diambil dari gelar Barong yang disakralkan di pura itu yaitu Barong Ratu Gede Empu Jagat.

2) Fungsi Pura Ratu Gede Empu Jagat ini mempunyai dua fungsi yakni fungsi religus dan fungsi sosial. Fungsi religus yaitu fungsi sebagai tempat suci untuk menghubungkan diri dan menyampaikan sujud bhakti ke hadapan Ida Sang Hyang Widhi dalam fungsinya sebagai Iswara (Siwa) dalam kemahakuasaan beliau sebagai penolak bala. Pura ini mempunyai fungsi sebagai tempat mohon Taksu (kekuatan yang membuat orang tertarik) bagi semua kesenian yang ada di Desa Pakraman Sangkaragung. Sedangkan fungsi sosial keberadaan Pura Ratu Gede Empu Jagat bagi masyarakat dapat dilihat dari kegiatan Ngayah yang dilaksanakan setiap piodalan di pura ini, dari kegiatan ini masyarakat antara satu sama yang lain dapat saling berinteraksi, dari yang kurang akrab mejadi akrab, dari yang agak renggang menjadi lebih dekat.

3) Makna umat keberadaan Pura Ratu Gede Empu Jagat di Desa Pakraman Sangkaragung yaitu: 1) dapat meningkatkan rasa bhakti umat terhadap Ida Sang Hyang Widhi, yang diwujudkan dengan pelaksaan upacara-upacara di pura ini.2) dapat meningkatkan kesucian desa dan Krama Desa Pakraman Sangkaragung baik lahir maupun batin dengan melaksanakan upacara Nyolahang(Ngelawang), mecaru, dan memperhatikan kebersihan, 
Jurnal Widya Sastra Pendidikan Agama Hindu, Vol 4, No. 1, 2021

ISSN: 2656-7466

tata busana, metirta, dan senantiasa menjaga kesucian pikiran. 3) meningkatkan dan melestarikan kesenian-kesenian yang ada di Desa Pakraman Sangkaragung.

\section{Saran}

1. Kepada masyarakat terutama generasi muda agar tetap melestarikan keberadaan pura Ratu Gede Empu Jagat.

2. Kepada pengurus pura membuatkan Purana tentang Pura Ratu Gede Empu Jagat sehinggga masyarakat dan generasi muda dapat memahami sejarah dibangunnya Pura Ratu Gede Empu Jagat.

3. Kepada pemimpin dan penentu kebijakan, disarankan pura ini diperbesar dan diperluas, struktur bangunan disesuaikan dengan struktur pura yang sesuai dengan konsep-konsep ajaran agama Hindu.

4. Kepada peneliti lain yang berniat, agar dapat dipakai sebagai pedoman atau acuan untuk mengembangkan aspek-aspek lain yang belum terjangkau agar hasil penelitian lebih sempurna.

\section{DAFTAR PUSTAKA}

Ardana, Nyoman. 2000. Fungsi Tirtha Taman dalam Upacara Potong Gigi di Desa Adat Samblong, Kecataman Jembrana, Kabupaten Jembrana. (Skripsi).

Astra, dkk. 1986. Kamus Sansekerta-Indonesia. Denpasar, Pemerintah Provinsi Bali.

Cudamani, 1989. Pengantar Agama Hindu. Jakarta: Yayasan Dharma Sarathi Jakarta.

Dinas Pendas, 1990. Kamus Bali Indonesia, Panitia Penyusun Bali Indonesia.

Donder, 2007. Filsafat IImu, Paramita.

Ktut Soebandi, 1983. Sejarah Pembangunan Pura-Pura di Bali, Kayu Mas Agung.

Kutha Ratna, 2013. Teori, Metode, dan Teknik Penelitian Sastra, Pustaka Pelajar.

Mahendra, Nyoman. 2005. Pura Tirtha Rambut Siwi di Desa Yehembang Kangin, Kecamatan Mendoyo, Kabupaten Mendoyo. (Skripsi).

Moleong, 2002.166. Metodologi Penelitian Kualitatif. Bandung, PT Remaja Rosdakarya.

Mantra, IB. 1981. Bhagawadgita, Parisada Hindu Dharma Pusat, Denpasar.

Netra, 1976. Metode Diskriptif, Pengolahan data Secara Umum.

Robert K. Merton. http:// teorifungsionalismestrktural.blogspot.

Sumarma, I Nengah. 1997. Tirha Penembak di Pura Gede Bakungan Kelurahan Sangkaragung, Kecamatan Jembrana, Kabupaten Jembrana. (Skripsi).

Sudana, Nyoman. 2013. Profil Pura di Desa Pakraman Sangkaragung, Kecamatan Jembrana, Kabupaten Jembrana. (Skripsi).

Swastika, I Ketut Pasek. 2008. Puja Tri Sandya-Panca Sembah, Arti dan Makna Bungan-ApiAir-Kwangen-Canangsari-Pejati, Penerbit CV. Kayumas Agung.

Suwenta, I Ketut. http:// jegogsuaragung.com/index.

Sutrisno, 2013. Metode Wawancara, Pengumpulan Data Melalui Wawancara.

Sudhrata, Tjokordo Rai. (ddk).2001, Pedoman Sembahyang, Paramita Surabaya.

Turner, 1990. Pengantar Teori Komunikasi, Salemba Empat

Titib, I Made. 1989. Pengertian Pura dan Tempat Suci di Bali, Manik Geni.

Titib, I Made. 2003. Teologi dan Simbol-Simbol Dalam Agama Hindu, Surabaya Paramita.

Wiana, I Ketut. 2007. Tri Hita Karana Menurut Konsep Hindu, Paramita Surabaya.

Yudabakti, I Made. 2007. Filsafat Seni Sakral dalam Kebudayaan Bali, Paramita Surabaya. 